\title{
PELATIHAN TATA KELOLA KEUANGAN UMKM
}

\author{
Elly Rahayu ${ }^{1}$, Risnawati ${ }^{2}$, Nurul Rahmadani $^{3}$ \\ ${ }^{1,2,3)}$ Program Studi Sistem Informasi STMIK Royal Kisaran \\ e-mail: ellyrahayu68@gmail.com
}

\begin{abstract}
Abstrak
KOOWE merupakan Usaha Mikro 1 milik bapak Herry Armansyah dan ibu Risna Oncu yang berlokasi di dusun 2B desa Silom-Lom Kecamatan Simpang Empat Kabupaten Asahan Sumatera Utara. Berdiri sejak tahun 2020. Dengan jenis usaha adalah pembuatan makanan ringan, diantaranya adalah Roket (Roti Ketawa) sebagai icon produk UMKM Koowe. Ada juga aneka Bolu, namun Roket menjadi produk andalan dari usaha 'KOOWE'. Dimulai dengan modal sendiri sebab masa itu belum dapat mengakses sumber permodalan dari perbankan.Usaha ini berjalan dengan order dari pelanggan, sejak berdiri pada tahun 2019, pelanggan tetap dari usaha KOOWE sudah mencapai 100 toko dan restoran. Di Kota Kisaran. Rata-Rata produsi Roket. $\pm 150 \mathrm{Kg}$ produksi. Karena Orderan yang terus meningkat dari bulan ke bulan, tambahan modalpun menjadi faktor yang perlu dipertimbangkan. Jika awal berdirinya pekerja adalah pemilik sendiri, kini pemilik usaha juga mempekerjaan ibu-ibu di sekitar rumah produksi sebagai pekerja harian. Jumlah pekerja saat ini 7 orang. Untuk mengakses permodalan ataupun pinjaman dari lembaga keuangan, tentunya pemilik harus mulai memiliki pencatatan keuangan meskipun masih sederhana, karena umumnya salah satu syarat administrasi adalah pengelolaan keuangan. Permasalahan usaha KOOWE adalah belum adanya pengelolaan keuangan yang baik. Oleh karenanya tujuan dari kegiatan PkM ini memberikan pengetauan tentang Tata Kelola Keuangan. Jenis kegiatannya adalah pelatihan dengan metode ceramah dan praktek/ simulasi pengelolaan secara langsung kepada pemiliki, yang sekaligus sebagai pengelola keuangan usaha KOOWE. Sehingga Usaha KOOWE ini kelak memiliki pencatata keuangan meskipun masih sederhana sehingga suatu saat dapat mengakses permodalan dari lembaga keuangaan
\end{abstract}

Kata kunci: UMKM, KOOWE, Tata Kelola, Manajemen, Keuangan

\begin{abstract}
KOOWE is a Micro Business owned by Mr. Heri Armansyah and Mrs. Risna Oncu which is located in the 2B hamlet of Silom-Lom village, Simpang Empat District, Asahan Regency, North Sumatra. Established in 2019. With this type of business, it is the manufacture of snacks, including Rocket (Ketawa Bread) as an icon for Koowe MSME products. There are also various Bolu, but Rocket is a mainstay product of the "KOOWE" business. Starting with their capital because at that time they could not access the source of capital from banks. This business is running with orders from customers, since its establishment in 2019, regular customers from the KOOWE business have reached 100 stores and restaurants. In Kisaran City. Rocket production average. $\pm 150 \mathrm{~kg}$ of production. Because orders continue to increase from month to month, additional capital is also a factor to consider. If the worker was the owner himself, now the business owner also employs women around the production house as day laborers. The number of workers is currently 7 people. To access capital or loans from financial institutions, of course, the owner must start to have financial records even though they are still simple because generally one of the administrative requirements is financial management. The problem with KOOWE's business is that there is no good financial management. Therefore, the purpose of this PkM activity is to provide insight into Financial Governance. The type of activity is training with lecture methods and management practice/simulation directly to the owner, who is also the manager of KOOWE's business finances. So that this KOOWE business will have financial records even though it is still simple so that one day it can access capital from financial institutions.
\end{abstract}

Keywords: UMKM, KOOWE, Governance, Management, Finance

\section{PENDAHULUAN}

Pertumbuhan UMKM di Indonesia yang terus meningkat tentunya merupakan angin segar bagi perekonomian Indonesia, karena akan berdampak pada perluasan lapangan kerja. Namun pertumbuhannya yang semakin meningkat tentunya bukan tanpa masalah. Berbagai permasalahan 
UMKM yang ada justru membuatnya kalah bersaing, jalan di tempat, hingga gulung tikar. Apa sebenarnya yang menjadi permasalahan utama dari UMKM di Indonesia? Terdapat lima (5) permasalahan utama mengapa UMKM kita kalah bersaing; (1) persoalan klasik adalah permodalan yang sangat terbatas. Menurut hasil penelitian Pricewaterhouse Coopers, yang mana 74\% UMKM di Indonesia belum mendapatkan akses pembiayaan. Banyak UMKM yang tidak mampu memenuhi persyaratan yang telah ditetapkan salah satunya adalah masalah pengelolaan keuangan (2) belum memiliki badan hukum yang jelas, selain masalah permodalan UMKM juga banyak yang belum memiliki izin usaha/badan hukum yang jelas, (3) rendahnya kesadaran membayar pajak, Dari sekitar 60 juta pelaku UMKM di Indonesia, hanya 2,5\% saja atau sekitar 1,5 juta pelaku UMKM yang melaporkan pajaknya apakah karena diabaikan atau mungkin keterbatasan sumberdaya manusianya yang menyebabkan banyak UMKM yang tidak mampu menghitung pajaknya sendiri (4) kurangnya inovasi . produk UMKM Indonesia kalah saing baik dari segi kualitas dan harga. Produk yang lahir dari latah atau ikut-ikutan tren ini tidak muncul dari konsep yang matang dan memiliki kemiripan satu sama lain dengan produk sejenis.dan (4) gagap teknlogi . Pertumbuhan teknologi yang cukup pesan sebenarnya merupakan peluang bagi UMKM untuk dapat menggunakan teknologi dalam memasarkan produknya, namun permasalahan muncul karena tidak semua pelaku UMKM mampu menggunakan teknologi. (Sandi, 2019).

Permasalahan yang dialami Usaha KOOWE tidak jauh berbeda dengan UMKM pada umumnya, yaitu usaha terus berjalan tanpa adanya informasi keungan yang dapat memberikan gambaran tentang perkembangan usaha. Belum adanya pencatatan usaha, kurangnya pengetahuan pemilik usaha tentang aplikasi pembukuan UMKM serta keterbatasan kemampuan pelaku usaha. Permasalahan inilah yang kemudian mendorong Tim Dosen STMIK Royal Kisaran untuk melakukan pelatihan Tata kelola keuangan UMKM sehingga kelak pelaku usaha mampu melakukan pencatatan keuangan meski sangat sederhana.

Tata kelola adalah kombinasi proses dan struktur untuk menginformasikan, mengarahkan, mengelola dan memantau kegiatan dalam rangka pencapaian tujuan. (Irawati et al., 2020) Marry Parker Foller dalam Irawati mendefinisikan tata kelola sebagai seni atau proses dalam menyelesaikan sesuatu yang terkait dengan pencapaian tujuan. (Irawati et al., 2020) Fungsi tata kelola atau manajemen keuangan itu sendiri terdiri dari tiga keutusan yang akan dilakuka oleh organisasi yaitu: keputusan investasi, pendanaan dan dividen.

Peserta kegiatan ini adalah Usaha Mikro KOOWE yang berlokasi di desa Silom-Lom Kecamatan Simpang Empat Kabupaten Asahan. Usaha ini dibanguan tahun 2020 bergerak dibidang pembuatan produk makanan ringan seperti Roti Ketawa (Roket), aneka bolu dan lain sebagainya sesuai permintaan konsumen. Saat ini telah memiliki lebih kurang 100 pelanggan tetap, memiliki 7 karyawan harian yang merupakan penduduk setempat. Pemilik usaha ini Ibu Risnawati Oncu. Produksi Roket dan aneka bolu lainnya lebih kurang $150 \mathrm{~kg}$ setiap bulannya. Bahkan pada saat lebaran dan hari hari besar lainnya mencapai $300 \mathrm{~kg}$.

Era digitalisasi saat ini menjadi peluang bagi usaha KOOWE untuk pengembangan dan perluasan usaha. Kendala yang dihadapi adalah pengelolaan keuangan yang masih dilakukan secara sederhana. Keinginan pemilik usaha adalah mempersiapkan usaha guna meghadapi tantangan UMKM kedepan. Digitalisasi dan penggunakaan teknologi bagi effisiensi usaha.

\section{METODE}

Identifikasi masalah menjadi langkah awal dari kegiatan Pengabdian masyarakat ini. Hasil diskusi dan interview singkat dengan pemilik usaha Bapak Herry Armansyah dan ibu Risna Oncu bahwa tata kelola keungan usaha menjadi hal yang harus dilakukan. Dari hasil identifikasi yang dilakukan, maka dirancanglah metode yang akan digunakan dalam kegiatan PkM ini. Metode yang digunakan dalam pelatihan ini adalaah metode ceramah, curah pendapat dan simulasi. Metode ceramah digunakan tim untukmemberikan pemahaman dan gambaran tentang pentingnya pengelolaan keuangan UMKM . Metode curah pendapatan dilakukan guna menggali informasi, permasalahan serta harapan-harapn pemilik usaha dalam memanfaatkan teknologi khususnya dalam bidang keuengan dan inovasi produk. Simulasi dilakukan guna mempraktekkan secara langsung penggunaan aplikasi keuangan usaha UMKM.Peserta kegiatan adalah pelaku usaha KOOWE berjumlah 7 orang (termasuk pemilik usaha). Dilakukan selama selama 3 hari pada tanggal 4-6 Maret 2021 (termasuk persiapan dan pelaksanaan kegiatan) 


\section{HASIL DAN PEMBAHASAN}

Kegiatan pengabdiana masyarakat ini dilaksanakan pada tanggal 4-6 Maret termasuk persiapan sampai dengan pelasnaan kegiatan. Untuk pelatihannya sendiri dilaksanakan pada tanggal 6 Maret 2021. Peserta kegiatan berjumlah 10 orang, 7 orang merupakan pelaku UMKM KOOWE dan 3 orang tim dosen. Lokasi pelaksanaan kegiatan adalah dilokasi usaha pelaku UMKM yang tepatnya berada di dusun 2B Desa Silom-Lom Kecamatan Simpang Empat Kabupaten Asahan. Dimulai pada jam 9 pagi dan dibagi dalam 2 sesi. Sesi-1 pemaparan materi Pengelolaan Keuangan UMKM, Materi kedua 5 Strategi Keuangan bagi pelaku UMKM agar bisnis tetap berjalan. Materi ketiga adalah Aplikasi Keuangan UMKM. Sesi-2 dilakukan setelah Ishoma pada jam 13.wib. Pada sesi-2 dilakukan simulasi langsung penggunaan salah satu aplikasi pembukuan UMKM.

Tabel 1.1 Materi Pelatihan Tata Kelola Manajemen Keuangan UMKM

\begin{tabular}{lll}
\hline No & Materi & Pemateri \\
\hline 1 & Pengelolaan Keuangan & Tim Dosen \\
2 & 5 Strategi Keuangan bagi Pelaku UMKM & Tim Dosen \\
3 & Aplikasi Pembukuan UMKM & Tim Dosen \\
4. & Simulasi penggunaan aplikasi pembukuan & Tim dosen \\
\hline
\end{tabular}

Pengelolaan keuangan UMKM, materi ini memaparkan tentang pentingnya pengelolaan keungan bagi UMKM. Usaha KOOWE yang dirintis sejak tahun 2020 terus mengalami perkembangan, saat ini produksi mencapai $150 \mathrm{Kg}$ setiap bulannya dengan jumlah pelanggan tetap lebih kurang 100 toko/restoran. Banyak praktek UMKM yang berjalan tanpa mengandalkan informasi keuangan yang dicatat secara tertib. a pelaku UMKM bergerak diberbagai bidang perekonomian. Permasalahan yang ditemukan adalah minimnya pengetahuan dan pemahaman mereka tentang akuntansi khususnya pencatatan dan pembukuan hingga penyusunan laporan keuangan. Pemahaman mereka sebelumnya bahwa pencatatan dan pembukuan itu sulit, merepotkan, dan menyita waktu menjadi penghambat untuk belajar akuntansi. Untuk itu pencatatan akuntansi berbasis teknologi menjadi penting terutama pada UMKM (Muljanto, 2020). Sehingga kelak pelaku UKM dapat mengetahui secara persis berapa pendapatan (kas) yang seharusnya diterima, berapa biaya operasi yang seharusnya dikeluarkan dan berapa yang seharusnya masih tersisa. Informasi keuangan yang baik juga bisa dijadikan sebagai dasar pengambilan keputusan.

Materi kedua yag juga dipaparkan oleh Tim dosen adalah 5 strategi keuangan bagi pelaku UMKM agar usaha tetap berjalan. Pandemi COVID-19 yang melanda seluruh belawhan bumi ini tentunya juga berdampak pada kemampuan bertahan. Untuk itu perlu diberikan pemahaman bagi pelaku UMKM strategi agar usaha tetap jalan dan mampu meminimalkan resiko kerugian. Materi yang diberikan berasala dari pengalamam beberapa pelaku UMKM yang sukses bertahan dan menjalankan usahanya dalam masa krisis beberapa tahun lalu.

Materi ketiga tentang aplikasi pembukuan UMKM.Beberapa aplikasi pembukuan yang dikenalkan adalah buku warung yang telah banyak dikenal oleh pelaku UMKM di Indonesia, Aplikasi Limkra; Aplikasi ini cocok untuk anda yang menginginkan pembukuan lengkap. Di aplikasi ini, Pembukuan meliputi neraca, laba rugi, arus kas dan rincian keuangan. Tidak perlu bingung, anda akan dibimbing mengisi setiap datanya. Selain itu, juga terdapat fitur pembukuan terkait pembelian aset, penghapusan piutang, setoran bank, dan masih banyak lainnya. Dan yang terakhir adalah aplikasi Akuntansi Keuangan; Aplikasi akuntansi (pencatatan informasi keuangan/SI APIK) bagi usaha mikro dan kecil. Aplikasi pembukuan ini dapat mencatat jenis transaksi sederhana bagi usaha perorangan (usaha mikro) maupun juga usaha kecil. Perbedaan pencatan usaha mikro dibandingkan usaha kecil terletak pada kompleksitas pencatatan dan laporan keuangan. Usaha Mikro hanya mencatat dan melaporkan sumber dan penggunaan dana, sementara usaha kecil menengah (UKM) menyusun laporan yang

Hasil dari pelatihan tata kelola keuangan UMKM khususnya pada Usaha KOOWE adalah peningkatan pemahaman pelaku usahan tentang pentingnyapencatatan traksasksi usaha yang baik untuk menghasilkan informasi keuangan dalam bentuk laporan keuangan sederhana. 

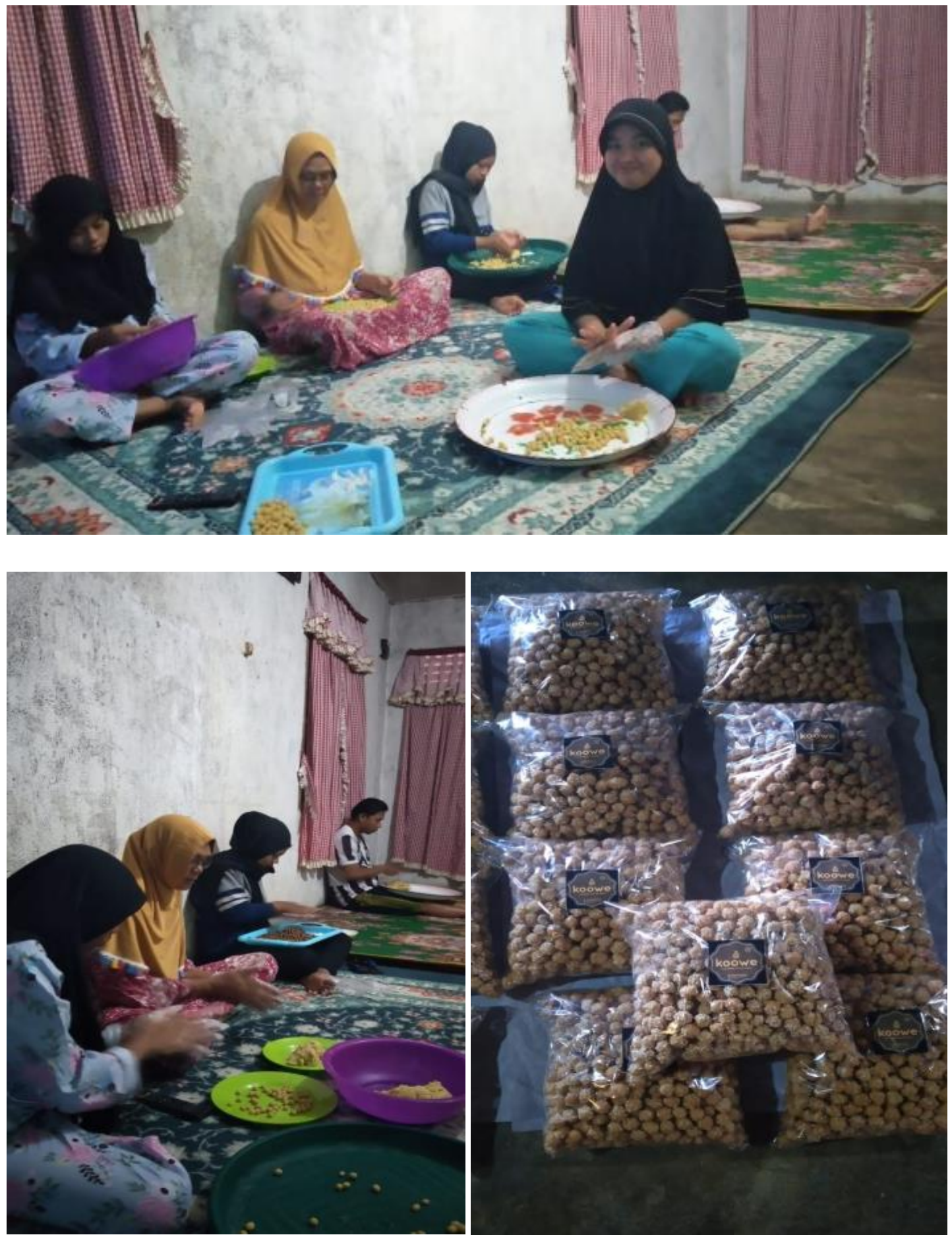

Gambar. Proses Pengerjaan KOOWE dari awal sampai dengan membungkus KOOWE

\section{SIMPULAN}

Telah dilaksanakannya kegiatan Pengabdian masyarakat tim dosen STMIK Royal pada tanggal 4-6 Maret 2021 dengan tema kegiatan Pelatihan Tata Kelola Keuangan UMKM, pada Usaha Mikro KOOWE yang berlokasi di Dusun 2B Desa Silom lom Kecamatan Simpang Empat Kabupaten Asahan. Peserta sebanyak 7 orang termasuk pemilik usaha yaitu bapak Herry Armansyah dan ibu Risna Oncu . Metode yang digunakan adalah ceramah, tukar pendapat dan simulasi/praktek aplikasi pembukuan. Meteri yag diberikan adalah Pengelolaan Keuangan UMKM, 5 Strategi Keuangan UMKM, Aplikasi Pembukuan UMPK dan simulasi. Kegiatan dibagi dua sesi; sesi pertama paparan materi dan sesi kedua simulasi aplikasi pembukuan. Hasil dari PkM ini adalah bertambahnya pengetahuan pelaku usaha tentang beberapa aplikasi keuangan UMKM yang bisa digunakan, pentingnya pengelolaan UMKM serta fungsi dari tata kelola keungan yang dilakukan. 


\section{SARAN}

Kedepan perlu dilakukan kerjasama yang lebih luas baik dengan pemerintah dan sektor swasta yang terkait dengan pengelolaan UMKM khususnya di wilayah Kabupaten Asahan sehingga kegiatan ini dapat dilakukan secara berkesinambungan. Perlu adanya koordinasi yang lebih intensif, menginggat banyak pelaku usaha UMKM yang buta teknologi baik untuk effisiensi produksi maupun teknologi yang terkait dengan pengelolaan keuangan seperti aplikasi akuntansi dan lainnya yang dapat membantu pelaku usaha mengukur kemajuan usahannya.

\section{UCAPAN TERIMA KASIH}

Ucapan terima kasih tak terhingga kepada semua pihak yang telah banyak membantu dari mulai perencanaan sampai pelaporan kegiatan, Kepada:

1. Ketua STMIK Royal, memberikan fasilitas serta izin untuk melakukan kegiatan pengabdian masyarakat

2. Ketua LPPM STMIK Royal yang telah memberikan dukungan moril serta sarana yang digunakan dalam kegiatan pengabdian ini

3. Pelaku Usaha KOOWE (Bapak Herry Armansyah dan Ibu Risna Oncu) yang memberikan izin tim dosen melakukan kegiatan pengabdian.

4. Seluruh pihak-pihak lain yang terlibat baik secara langsung maupun tidak langsung

\section{DAFTAR PUSTAKA}

Irawati, W., Indrayani, L., \& Barli, H. (2020). Tata Kelola Keuangan Sederhana bagi UMKM di Kapuk Muara. ABDIMASKU: JURNAL PENGABDIAN MASYARAKAT, 3(3). https://doi.org/10.33633/ja.v3i3.130

Muljanto, M. A. (2020). Pencatatan dan Pembukuan Via Aplikasi Akuntansi UMKM di Sidoarjo. Jurnal Ilmiah Pangabdhi, 6(1). https://doi.org/10.21107/pangabdhi.v6i1.6926

Sandi, F. B. (2019). 5 Permasalahan UMKM yang Sering Terjadi di Indonesia dan Solusinya. Online Pajak. 